\title{
WAKEFIELDS AND DRIVE ELECTRON BUNCHES DYNAMICS IN THREE-ZONE DIELECTRIC RESONATOR AT ASYMMETRICAL INJECTION
}

\author{
K.V. Galaydych, R.R. Kniaziev, G.A. Krivonosov, I.N. Onishchenko, G.V. Sotnikov \\ National Science Center “Kharkov Institute of Physics and Technology”, Kharkiv, Ukraine \\ E-mail: galaydych@kipt.kharkov.ua
}

A numerical study of the wakefield excitation in a rectangular dielectric-loaded resonator by a sequence of relativistic electron bunches in the case of non-axial injection is carried out. The effect of the shift of injected bunches on the particle dynamics, as well as on the spatial distribution of the components of the bunch-excited fields, is studied. The current losses of a sequence of relativistic electron bunches due to the particles deposition on the surface of the dielectric is determined.

PACS: 41.75.Lx, 41.60.-m, 41.75.Ht, 41.85.Ar

\section{INTRODUCTION}

Promising methods of charged particles acceleration, theoretical and experimental studies of which are carried out in many leading accelerating centers of the world, include acceleration by the wakefields, excited by the relativistic electron bunches in the dielectric structures. There are several motivations for this. On the one hand, the limits of electric field strength and power level for traditional (conventional) acceleration schemes have been reached. On the other hand, there are recent advances in technology of artificial dielectric materials manufacture capable of operating at high levels of highfrequency breakdown, as well as advances in the formation of high-charge short bunches. Dielectric waveguide structures can use these advances in order to overcome the abovementioned problems to solve electromagnetic field excitation problems with both higher field amplitude and frequency.

The simplest dielectric structure is a segment of a cylindrical waveguide, which is partially filled by a homogeneous isotropic dielectric material with a vacuum channel along its axis for charged particles passing. Despite the fact that high precision requirements are imposed in the manufacture and tuning of such structures, most theoretical studies are devoted to such structures. This fact is explained that the dispersion characteristics of such structures, as well as the topography of the components of the electric and magnetic fields of eigenwaves, are well studied. Recently, more attention has been paid to studies of accelerating structures having planar and rectangular configurations, so-called multizone dielectric structures with dielectric slabs and vacuum channels for charged particles [1 - 9]. Planar structures differ from rectangular ones in that their size in one of the transverse directions significantly exceeds the size in the other transverse direction. Such structures have a number of technological advantages over cylindrical in manufacture and tuning. One of the advantages of rectangular dielectric accelerating structures is that the working mode in such a structure can be selected with a symmetrical distribution of the longitudinal component of the electric field in the transverse direction in the vacuum channel. As a consequence, this reduces the transverse forces acting on both the driver bunches and a test bunch. This increases the efficiency of both the excitation of the accelerating structure and further test electron bunch acceleration.
One of the key issues of the accelerators development is a transverse stability of the bunches. In the case of dielectric wakefield accelerators, this issue is especially important because the electromagnetic field is excited by the same bunches, not by an external highfrequency source, as in conventional accelerators. As a consequence of this instability, in addition to the bunches parameters degradation (such as transverse size and energy spread increasing, etc.), it is also possible a particles deposition on the dielectric surface. In turn, this will lead to change in dielectric material parameters and, as a consequence, the detuning of the Cherenkov resonance conditions. An important case of transverse instability is asymmetric bunch injection. Theoretical studies of wakefields excitation in dielectric structures under asymmetric electron bunches injection, carried out so far, were performed in a waveguide problem statement [10 - 13], without taking into account the finite length of the accelerating structure. In a resonator, unlike a waveguide, all the bunches of regular sequence are involved in the total electromagnetic field formation and for the accumulation of electromagnetic field energy from a large number of bunches, that are regularly injected, the most effective is the use of dielectric resonators $[14,15]$. Therefore, issues related to the effects, affecting the transverse charged particles dynamics, require detailed theoretical analysis for future recommendations of appropriate dielectric accelerating resonator structures experimental development. Foregoing determines the relevance and necessity of the presented theoretical studies.

\section{STATEMENT OF THE PROBLEM}

The three-zone dielectric structure, the excitation of which is planned in future experimental studies at Kharkiv Institute of Physics and Technology, is a rectangular metal resonator, parallel to one of the sides of which dielectric slabs are placed. Overview of the structure under study is shown schematically in Fig. 1. The resonator is a segment of a rectangular waveguide, the ends of which are closed by metal grids. Electron bunches are injected into the resonator vacuum channel. We assume that the input and output of the resonator are transparent for charged particles and non transparent for the electromagnetic field, excited by the bunches. 


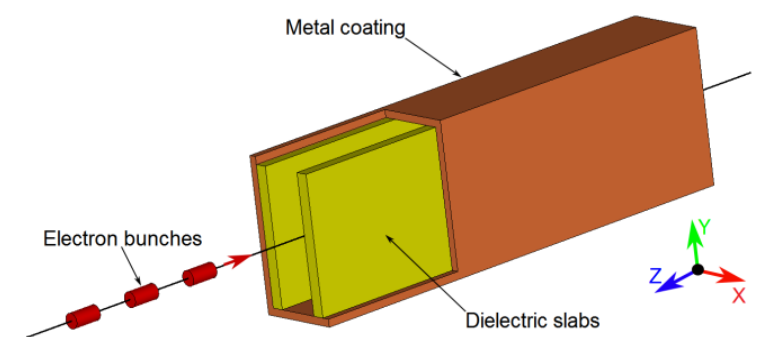

Fig. 1. Overview of a dielectric rectangular resonator. The metal coating, dielectric slabs, and electron bunches (moving from left to right and exciting

the electromagnetic field) are shown schematically

The main goal of the simulations was to study the dynamics of wakefields and drive relativistic electron bunches (which excite the electromagnetic field) in the case of their asymmetric injection with respect to the axis of the structure (Fig. 2).

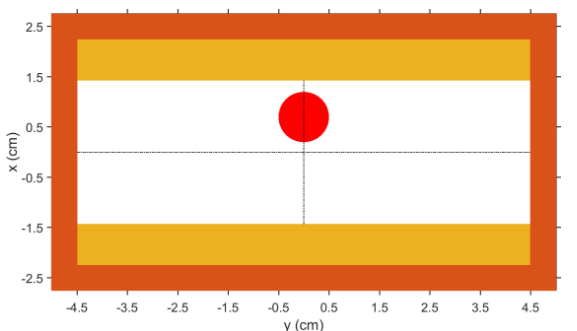

Fig. 2. Cross section of the dielectric resonator.

The location of the metal coating, dielectric slabs, and electron bunch, injected with an offset, are shown

For numerical analysis the following parameters were chosen. A bunch charge is $6.4 \mathrm{nC}$, an energy of bunch electrons is $4.5 \mathrm{MeV}$, the bunch sizes: diameter is $1.0 \mathrm{~cm}$, length is $1.88 \mathrm{~cm}$. The offset of the bunches is $0.9 \mathrm{~cm}$. The transverse parameters of the resonator are as follows: the width of the resonator is $4.5 \mathrm{~cm}$, the height of the resonator is $9.0 \mathrm{~cm}$; dielectric slabs thickness is $0.82 \mathrm{~cm}$; vacuum channel width is $2.86 \mathrm{~cm}$; dielectric constant (teflon) $\varepsilon=2.051$, magnetic constant $\mu=1$. The length of the resonator was chosen such that it was equal to six wavelengths of a resonant with the bunches eigenmode $L M_{21}$ (the transverse distribution of the axial component of which is symmetric in the vacuum channel), and was $31.92 \mathrm{~cm}$. This choice of the parameters provided the conditions of a concept of resonant wakefield accelerator [17]. For the PIC simulations CST Particle Studio was used [18].

\section{SIMULATION RESULTS}

First of all a spectral analysis of the bunch-excited electromagnetic field was performed. It is shown that in the case of a single electron bunch, the spectrum of the electromagnetic field is densely filled with many eigen frequencies of the dielectric resonator (Fig. 3, right plot). The wide frequency spectrum is the result of the excitation of a large number of non-resonant frequencies, which can be interpreted as a field of transient radiation excited by an electron bunch during injection and exit from the resonator. The largest amplitudes in the spectrum correspond to the frequency of the $L M_{21}$ mode, which is in resonance with the bunch and modes, which are close to this frequency.

The bunch sequence by amplifying resonant mode modes with frequencies close to multiple resonant freISSN 1562-6016. BAHT. 2019. №6(124) quencies, and suppression of nonresonant modes, monochromatizes the spectrum of the field, excited in the resonator (see left plot in Fig. 3).
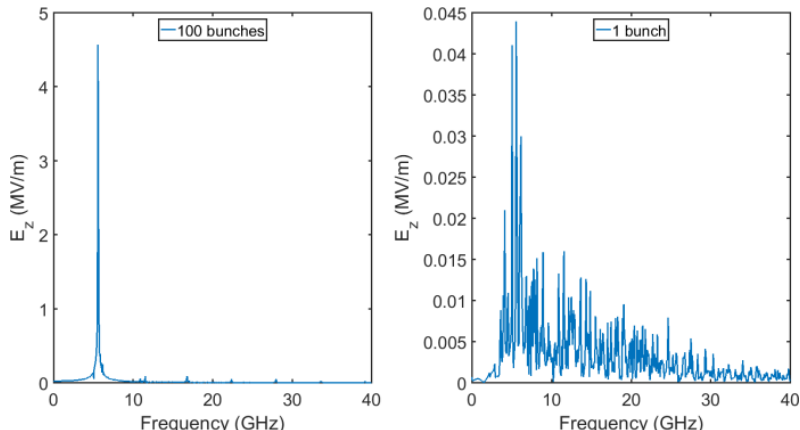

Fig. 3. The spectrum of a longitudinal electric field, excited by a sequence of 100 bunches (left). The spectrum of a longitudinal electric field, excited by the single electron bunch (right)

The distribution of the axial and transverse components of the bunch-excited electric and magnetic fields, both in the longitudinal (with respect to the direction of the bunch motion) and in the transverse directions, was obtained and analyzed as well.
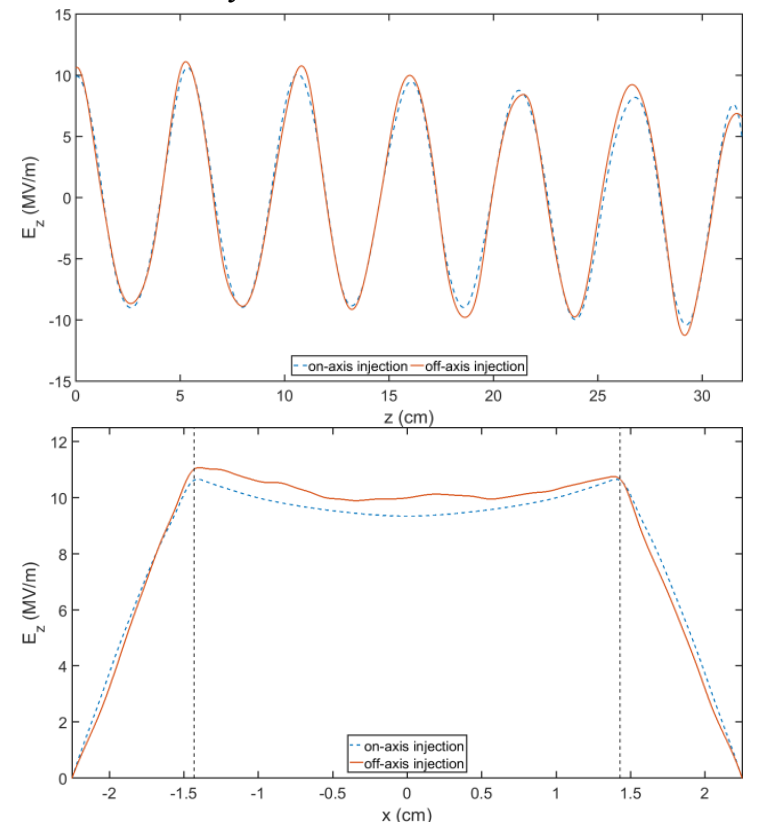

Fig. 4. (top) Longitudinal and (bottom) transverse distribution of the axial component of the electric field, excited by the sequence of 100 electron bunches.

The vertical dashed lines indicate the position of the dielectric slabs

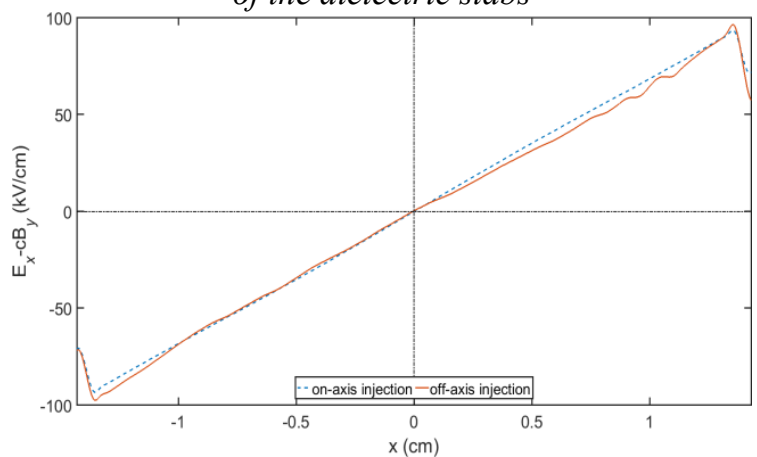

Fig. 5. Transverse distribution of the transverse force (perpendicular to the dielectric slabs) in the vacuum channel, excited by the sequence of 100 electron bunches 
Figs. 4 and 5 demonstrate the axial and transverse distribution of the longitudinal component of the electric field, as well as the transverse distribution of the transverse force, excited in the resonator by a sequence of 100 electron bunches for the cases of the on-axis injection, and for the off-axis injection.

As the number of electron bunches injected into the resonator increases, the amplitude of the electric field in the resonator increases, and in the longitudinal and transverse directions becomes more monotonic with characteristic spatial periods of the resonant mode. In this case, the electromagnetic field changes over time so that the electron bunches remain in the decelerating phases of the field, continuing to transfer it energy. The increase of the amplitude of the electric field longitudinal component in the case of asymmetric bunch injection is associated with an increase in the coupling between the resonance mode and the bunches (the resonance mode amplitude is maximum at the dielectric surface and minimum at the resonator axis). It can be seen, that even for significant bunches offset $(0.9 \mathrm{~cm})$ the spatial distribution of the field components stay almost the same (in comparison with on-axis injection). A slight deformation of the profiles of the electromagnetic field components is associated with the excitation of the resonator oscillations with frequencies, that are multiples of the repetition rate of the bunches.

The dynamics of drive bunches, injected off-axis, was investigated in detail both in the transverse and longitudinal directions. A comparison with the case of on-axis injection was carried out as well. For a clear understanding of the bunches dynamics Fig. 6 demonstrates the position of the bunches in the vacuum channel for consecutive time moments. The positions of the particles are given in the horizontal and vertical planes. The first moment corresponds to the moment when the last bunch of the sequence is fully injected into the resonator, the last - when this bunch reaches the exit of the resonator. A characteristic feature of the working mode of the resonator, on which is the excitation by the sequence of bunches, is the simultaneous focusing in one transverse direction, and defocusing in another. In which of two transverse directions is focusing, and in which is defocusing depends on the phase of the particle relative to the field of resonant mode of oscillation. Fig. 6 shows that as the bunches pass along the resonator vacuum channel, a part of each bunch is focused, and another part is defocused in the respective transverse directions.

The corresponding dynamics of the bunches (in the horizontal plane only) in the case of off-axis injection is shown in Fig. 7.

Compared to injection along the axis, there are no qualitative differences in the bunches dynamics in the vertical plane.

Significant qualitative differences take place only in the horizontal plane. Because the bunch sequence enhances the resonant mode with symmetric (transverse) field distribution, and suppresses modes with asymmetric distribution, the bunches are not deflected as a whole in the dielectric slabs direction. Due to focusing a significant part of each bunch is back on the axis of the resonator.
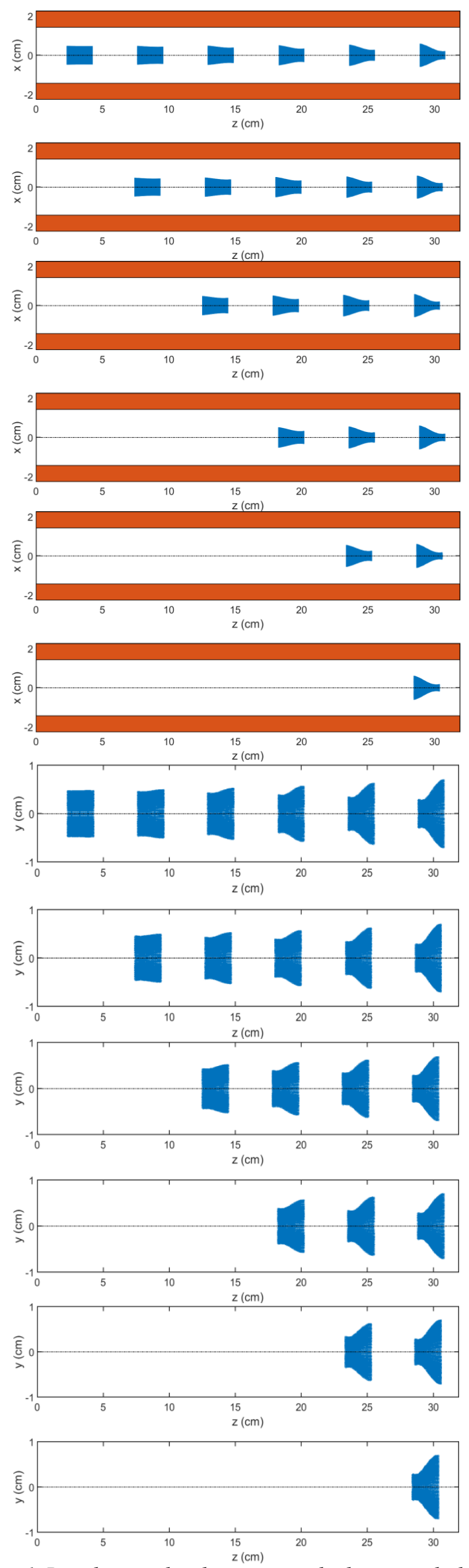

Fig. 6. Bunch particles dynamics in the horizontal plane in the case of injection along the axis of the resonator for six consecutive time moments after injection of the last bunch of the sequence 

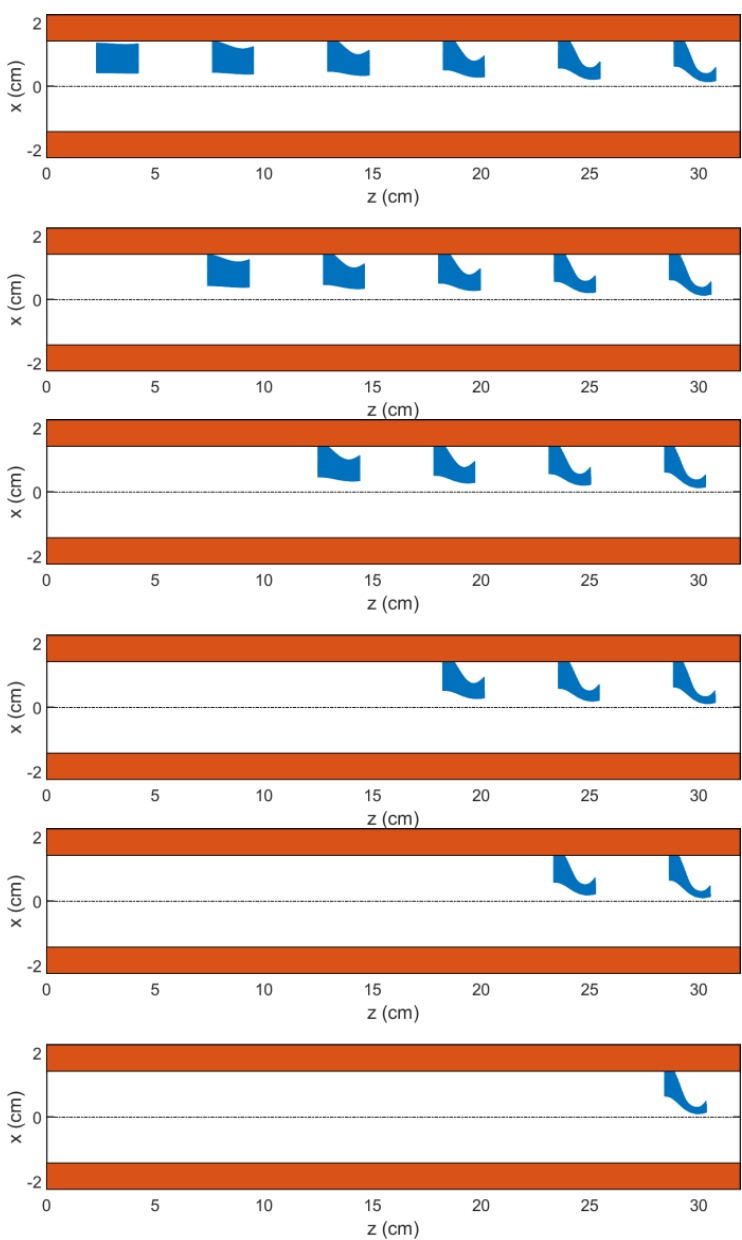

Fig. 7. Bunch particles dynamics in the horizontal plane in the case of asymmetric injection for six consecutive time moments after injection of the last bunch of the sequence

Fig. 7 demonstrates that the charge losses occur for the bunch particles located on its periphery, therefore, the bunches charge loss should not be significant.

As a quantitative characteristic of charge losses due to the deposition of particles on the dielectric, the current of the bunch sequence at the input of the resonator, at its output, and on the surface of the dielectric slab (towards which the bunches are shifted) was analyzed. The corresponding dependencies are presented in Fig. 8. Comparing the above currents, we can conclude that current through the surface of the dielectric slab does not tend to increase with time, that is, a gradual increase in charge losses does not occur.
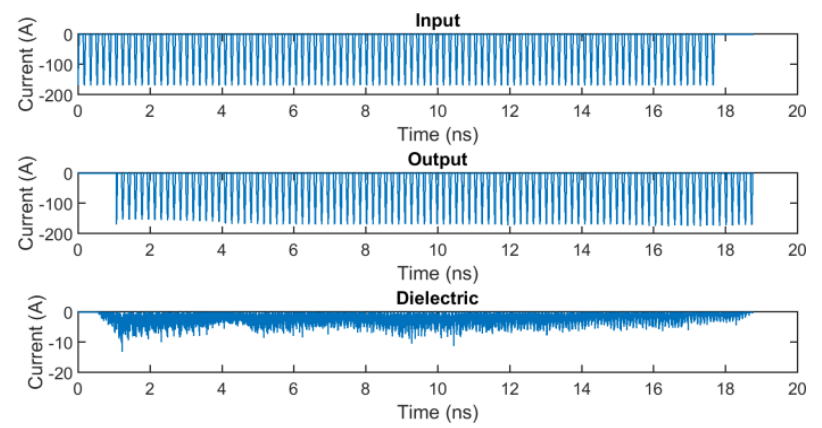

Fig. 8. Input current (top), current at the output of the resonator (middle) and full current through the surface of the dielectric slab (bottom)
The preliminary conclusion of this behavior is as follows. This is due to the increasing sequence of resonant mode with symmetric field distribution, and the suppression of modes with asymmetric distribution, which (in the case of their large excitation) make a major contribution to the force that displaces electron bunches as a whole.

\section{CONCLUSIONS}

A numerical study of the wakefield excitation in a three-zone rectangular dielectric resonator with asymmetric injection of a regular sequence of the relativistic electron bunches was performed. The Fourier analysis of the electromagnetic field, excited in the resonator, showed that the maximum in the spectrum corresponds to the resonant frequency of the bunch repetition, the amplitudes of the higher modes are excited much weaker. It is shown that the presence of horizontal bunches displacement does not significantly affect on the spatial distribution of the electromagnetic field components, excited in the resonator. The analysis of the transverse dynamics of the electron bunches, as well as the current analysis through the surface of the dielectric slabs, demonstrated that the increase of current losses per dielectric slabs does not occur over time, and thus is not a critical factor which requires high injection accuracy for the future development of the resonant wakefield accelerator.

\section{ACKNOWLEDGEMENT}

This work was supported by NAS of Ukraine, the program "Perspective researches on plasma physics, controlled thermonuclear fusion and plasma technologies" (Project P-1/63-2017), and by the Ukrainian budget program "Support for the most important directions of scientific researches" (КПКВК 6541230).

\section{REFERENCES}

1. A. Tremaine, J. Rosenzweig, P. Schoessow. Electromagnetic wakefields and beam stability in slabsymmetric dielectric structures // Phys. Rev. E. 1997, v. 56, № 6, p. 7204-7216.

2. T.B. Zhang, J.L. Hirshfield, T.C. Marshall, B. Hafizi. Stimulated dielectric wakefield accelerator // Phys. Rev. E. 1997, v. 56, № 4, p. 4647-4655.

3. S.Y. Park, J.L. Hirshfield. Bunch stability during high-gradient wakefield generation in a dielectriclined waveguide // Physics of plasmas. 2001, v. 8, № 5, p. 2461-2465.

4. S.Y. Park, C. Wang, J.L. Hirshfield. Theory for wakefields and bunch stability in planar dielectric structures // AIP Conference Proceedings. 2002, v. 647, № 1, p. 527-541.

5. T.C. Marshall, C. Wang, J.L. Hirshfield. Femtosecond planar electron beam source for micron-scale dielectric wakefield accelerator // Phys. Rev. ST Accel. Beams. 2001, v. 4, № 12, p. 121301.

6. L. Xiao, C. Jing, W. Gai, T. Wong. Wakefields in dielectric-loaded rectangular waveguide accelerating structures // AIP Conference Proceedings. 2002, v. 647, № 1, p. 542-555.

7. T.C. Marshall, J.-M. Fang, J.L. Hirshfield, et al. Wakefields excited in a micron-scale dielectric rec- 
tangular structure by a train of femtosecond bunches // AIP Conference Proceedings. 2002, v. 647, № 1, p. 361-370.

8. C. Wang, J.L. Hirshfield, J.-M. Fang, T.C. Marshall. Strong wakefields generated by a train of femtosecond bunches in a planar dielectric microstructure // Phys. Rev. ST Accel. Beams. 2004, v. 7, № 5, p. 051301 .

9. L. Xiao, W. Gai, X. Sun. Field analysis of a dielectric-loaded rectangular waveguide accelerating structure // Phys. Rev. E. 2001, v. 65, № 1, p. 016505.

10. D. Mihalcea, P. Piot, P. Stoltz. Three-dimensional analysis of wakefields generated by at electron beams in planar dielectric-loaded structures // Phys. Rev. ST Accel. Beams. 2012, v. 15, № 8, p. 081304.

11. C. Li, W. Gai, C. Jing, J.G. Power, C.X. Tang, and A. Zholents. High gradient limits due to single bunch beam breakup in a collinear dielectric wakefield accelerator // Phys. Rev. ST Accel. Beams. 2014, v. 17, № 9, p. 091302.

12. W. Gai, A.D. Kanareykin, A.L. Kustov, J. Simpson. Numerical simulations of intense charged-particle beam propagation in a dielectric wake field accelerator // Phys. Rev. E. 1997, v. 55, № 3, p. 34-81.
13. S.S. Baturin, A. Zholents. Stability condition for the drive bunch in a collinear wakefield accelerator // Phys. Rev. ST Accel. Beams. 2018, v. 21, № 3, p. 031301.

14. A.M. Altmark, A.D. Kanareykin. Annular Cherenkov high gradient wakefield accelerator: beambreakup analysis and energy transfer efficiency // Journal of Physics: Conference Series. 2012, v. 357, p. 012001.

15. V.A. Balakirev, I.N. Onishchenko, D.Yu. Sidorenko, G.V. Sotnikov. Uskorenie zaryazhennyx chastic kilvaternymi polyami $\mathrm{v}$ dielektricheskom rezonatore s kanalom dlya vozbuzhdayushhego sgustka // Pisma v ZTF. 2003, v. 29, № 14, p. 39 (in Russian).

16. T.C. Marshall, J.-M. Fang, J.L. Hirshfield, S.-Y. Park. Multi-mode, multi-bunch dielectric wakefield resonator accelerator // AIP Conference Proceedings. 2001, v. 569, № 1, p. 316-325.

17. I.N. Onishchenko, G.V. Sotnikov. Sinxronizaciya kilvaternyx mod $\mathrm{v}$ dielektricheskom rezonatore // ZTF. 2008, v. 78, № 10, p. 96-102.

18. CST PS, http://www.cst.com

Article received 28.10.2019

\section{ДИНАМИКА КИЛЬВАТЕРНЫХ ПОЛЕЙ И ДРАЙВЕРНЫХ ЭЛЕКТРОННЫХ СГУСТКОВ В ТРЕХЗОННОМ ДИЭЛЕКТРИЧЕСКОМ РЕЗОНАТОРЕ ПРИ НЕСИММЕТРИЧНОЙ ИНЖЕКЦИИ}

\section{К.В. Галайдыч, Р.Р. Князев, Г.А. Кривоносов, И.Н. Онищенко, Г.В. Сотников}

Проведено численное исследование возбуждения кильватерного поля в прямоугольном диэлектрическом резонаторе последовательностью релятивистских электронных сгустков в случае несимметричной инжекции. Изучено влияние сдвига инжектируемых сгустков на динамику частиц, а также на пространственное распределение компонент возбуждаемого электромагнитного поля. Определены потери тока последовательности электронных сгустков вследствие осаждения частиц на поверхность диэлектрика.

\section{ДИНАМІКА КІЛЬВАТЕРНИХ ПОЛІВ ТА ДРАЙВЕРНИХ ЕЛЕКТРОННИХ ЗГУСТКІВ У ТРЬОХЗОННОМУ ДІЕЛЕКТРИЧНОМУ РЕЗОНАТОРІ ЗА УМОВИ АСИМЕТРИЧНОЇ ІНЖЕКЦІЇ К.В. Галайдич, Р.Р. Князєв, Г.О. Кривоносов, І.М. Оніщенко, Г.В. Сотніков}

Проведено числове дослідження збудження кільватерного поля в прямокутному діелектричному резонаторі послідовністю релятивістських електронних згустків за умови асиметричної інжекції. Вивчено вплив зсуву згустків, що інжектуються, на динаміку частинок, а також на просторовий розподіл компонент електромагнітного поля, що збуджується. Визначено втрати струму послідовності електронних згустків внаслідок осадження частинок згустків на поверхню діелектрика. 